\title{
Standard Score Comparison 2.0: Second-generation learning disability regression software
}

\author{
LARRY D. EVANS \\ University of Arkansas for Medical Sciences, Little Rock, Arkansas
}

\begin{abstract}
As states increasingly adopt actuarial models to aid learning disability (LD) identification, microcomputer programs are being used to accurately measure the primary LD criterion: severe discrepancies between IQ and achievement. First-generation programs offered little flexibility in regression parameters and user-defined options. This paper describes Standard Score Comparison 2.0 (SSC 2.0), a second-generation regression program that calculates multiple discrepancies, and provides options for Type I error rates, SEM confidence levels, correction for multiple comparisons, and the cut-off value that defines severe discrepancy. Application of SSC 2.0 to non-LD areas and potential features of third-generation software are discussed.
\end{abstract}

Federal guidelines for learning disability (LD) determination consist of three components: provision of appropriate education experiences, a severe discrepancy between IQ and at least one of seven achievement areas, and exclusion of sensory deficits and other disorders as causes of the severe discrepancy (U.S. Office of Education, 1977). States have increasingly adopted the Federal guidelines; from 1976 to 1988 , state LD definitions including the severe discrepancy component increased from $29 \%$ to $88 \%$ (Frankenberger \& Fronzaglio, 1991; Mercer, King-Sears, \& Mercer, 1990). Unfortunately, Federal guidelines did not operationalize severe discrepancy, and states have utilized a variety of discrepancy models (e.g., deviation from grade or age level, expectancy formulas, simple standard score comparison, regression analysis) to assess discrepancy magnitude and severity. Even within models, a variety of equations have been used with great variability in results (Forness, Sinclair, \& Guthrie, 1983).

Statistical inadequacies of the early discrepancy models included the use of ordinal data for IQ-achievement comparisons and a lack of consideration for regression toward the mean (Reynolds, 1984). These inadequacies have resulted in an increased use of more complex regression discrepancy models (Frankenberger \& Fronzaglio, 1991). Such models comprise equations to predict expected achievement on the basis of IQ, to define the discrepancy magnitude as the difference between expected and obtained achievement, to determine the discrepancy's statistical significance, to calculate the standard deviation and standard error of measurement of the discrepancy, and to compare the discrepancy's magnitude and standard deviation to determine severity (Evans, 1990). Regression models are currently recognized

Standard Score Comparison 2.0 is available from WtL Publishing, 6929 JFK Blvd., Suite 20-120, North Little Rock, AR 72116. Address correspondence to L. D. Evans, Psychology Department, 1612 Maryland St., Little Rock, AR 72202 . as the most statistically adequate type of model for determining severe IQ-achievement discrepancies, although concerns have been expressed regarding the model's results (e.g., consistency across various tests-Macmann, Barnett, Lombard, Belton-Kocher, \& Sharpe, 1989; and potential for overreliance during LD determination-Hammill, 1990).

\section{FIRST-GENERATION REGRESSION MODEL SOFTWARE}

The numerous equations of the regression model cannot be calculated reliably by hand. As a result, early regression model use by states involved tables for pairs of IQ and achievement measures that provided a cut-off achievement score for severe discrepancy according to student age and IQ (Iowa Department of Public Instruction, 1981; Washington Office of Public Instruction, 1984). Unfortunately, the tables offered little flexibility in test selection, discrepancy parameters, or consideration of measurement error. First-generation regression model software (e.g., Evans \& Hilden, 1986; Furlong, 1985; Reynolds \& Stowe, 1985 ) allowed greater flexibility by permitting standard scores from any measure, considering measurement error, and offering limited control of discrepancy parameters. These first-generation regression programs were adopted as best practice procedures by states (e.g., Montana), practitioners, and researchers.

Although first-generation regression programs offered advantages over hand calculation and tables, numerous problems and limitations with regression models became evident. First, initial regression model equations assessing the statistical significance of IQ-achievement discrepancies required revision to be fully compatible with remaining equations (Evans, 1992b). Second, the few models that attempted to control for multiple IQ-achievement comparisons (Furlong, 1985; Tomko \& Campbell, 1989) did so by ad: justing the critical value for severity rather than during sig- 
nificance testing (Evans, 1992a). Third, model equations were based on a single IQ-achievement comparison, requiring several runs of a program to compare all achievement scores from a general achievement measure. Fourth, although some models considered measurement error, results of severe discrepancy determination were typically given as "yes" or "no" without any indication of the probability that a severe discrepancy existed. Fifth, the models recommended specific values for Type I error, confidence levels, and critical values, and provided limited ability to use alternative values. Sixth, few programs included regression model data (test means, standard deviations, reliabilities) for popular IQ and achievement tests. The programs that included these data also allowed use of alternative tests, but the included tests could not be deleted, updated, or replaced.

\section{STANDARD SCORE COMPARISON 2.0}

Standard Score Comparison 2.0 (SSC 2.0; Evans, 1991) represents a second generation of regression model software. A decade of regression model research and education has created a need for software such as SSC 2.0 that can be adapted more easily to individual school district severe discrepancy conceptualization and parameters. SSC 2.0 is available for IBM (PC, XT, x86), Macintosh (Plus and later models), and Apple $\mathrm{\Pi e} / \mathrm{c} / \mathrm{gs}$ computers and is written in Microsoft QuickBASIC (IBM, Macintosh) and BASIC (Apple). The program's run time averages $5 \mathrm{~min}$, and the results are displayed in screen and printer formats.

As opposed to first-generation regression model software, SSC 2.0 includes the following features:

1. Commonly used test data (means, standard deviations, reliabilities, intercorrelations) can be stored within easily updated and modified tables. The first table saves data for 15 predictor (e.g., intelligence) measures, and a second table stores data for as many as 5 subtests from 15 criterion (e.g., achievement) measures. A third table saves intercorrelation values between predictor and criterion measures.

2. The initial regression model equation that assesses the significance of IQ-achievement discrepancies has been revised (Evans, 1992b; Thorndike, 1963), and options for overall Type I error rates are provided that are based on correction $(.01, .05, .10$, or .20$)$ or no correction $(.001$, $.005, .01, .05, .10, .15$, or .20 ) for multiple comparisons.

3 . The critical value for severe discrepancy (the number of discrepancy standard deviations required for the discrepancy to be considered severe) can assume any decimal value between 0 and 10 . Adjusting this value can affect severe discrepancy rates and SSC 2.0 interpretive statements, such as the probability that a severe discrepancy exists.

4. The discrepancy's standard error of measurement can be considered to determine whether, with measurement error, the discrepancy meets or exceeds the critical value. SSC 2.0 allows consideration of $0 \%, 68 \%, 80 \%, 85 \%$, $90 \%, 95 \%$, or $99 \%$ of measurement error.

5 . In order to interpret the discrepancy's magnitude and the relationship between measurement error and the crit- ical value, SSC 2.0 provides information regarding the discrepancy's prevalence in a normal population and the probability that the discrepancy exceeds the critical value.

6. SSC 2.0 performs up to five IQ-achievement comparisons in one run. If test data have been entered into the tables and if no changes to program options (Type I error rates, amount of measurement error to be considered, critical value) are needed, users enter only identifying data (student name, etc.) and the standard scores for the IQ and achievement measures.

\section{Output}

SSC 2.0 provides screen and printed output. An example of the printed output is shown in Figure 1: a single page output is provided with identifying data, and program options are displayed for reference. Next, the results of significance testing between expected (predicted) and obtained achievement are presented; these are based on the selected Type I error rate and any correction for multiple comparisons. Results of severity testing are presented last. Discrepancies that were not significant cannot be severe. Discrepancy sizes, minimum discrepancy size required for severity, probability of severity, and normal population prevalence are given. If the discrepancy meets or exceeds the minimum size, SSC 2.0 indicates "yes"-the discrepancy may be severe.

\section{Application to Non-LD Areas}

In its present form, SSC 2.0 is a generic program with application beyond learning disabilities. Since September 1991, Arkansas speech and language pathologists have used SSC 2.0 to evaluate the significance of differences between predicted language scores (based on IQ) and obtained language scores to aid them in making therapyeligibility decisions. Similarly, SSC 2.0 can be used to determine whether obtained adaptive behavior scores of mental retardation evaluations are significantly different from those expected on the basis of IQ.

Regardless of the suspected handicapping condition, SSC 2.0 can help in the analysis of strengths and weaknesses. For skills thought to be normally distributed, SSC 2.0 can specify whether obtained scores are significantly above or below levels expected from a single predictor (e.g., IQ). If differences are significant, SSC 2.0 severity results can provide information about how uncommon such a strength or weakness is in a normal population.

\section{LIMITATIONS: THE NEXT GENERATION}

Continued adoption of and interest in regression models may lead to the development of a third generation of regression model software. Such software will need to address the levels of user education and sophistication at that time, but it is likely that the following features will be included:

1. All seven severe discrepancy areas. SSC 2.0 simultaneously analyzes up to five discrepancies, which covers the most popular severe discrepancy areas. However, there are seven severe discrepancy areas and new tests 
STANDARD SCORB COMPARISON

REGRESSION PROGRAM RESULTS

IDBNTIFYING DATA

$\begin{array}{ll}\text { Child Name: } & \text { John Doe } \\ \text { Date of Bvaluation: } & 92 / 11 / 23 \\ \text { Date of Birth: } & 82 / 10 / 11 \\ \text { Age: } & 10 / 1 / 12 \\ \text { Bvaluator: } & \text { Swith }\end{array}$

OPTION SETTINGS

$\begin{array}{lr}\text { Significance tests corrected for multiple comparisons? } & \text { Yes } \\ \text { Overall Type I error rate for multiple, corrected comparisons: } & .10 \\ \text { Acceptable Type I error rate for single, uncorrected comparisons: } & .050 \\ \text { Number of standard deviations considered severes } & 2.00 \\ \text { Discrepancy includes consideration for measurement error? } & \text { Yes } \\ \text { Percent of measurement error considered: } & 95\end{array}$

SIGNIFICANCE RESULTS

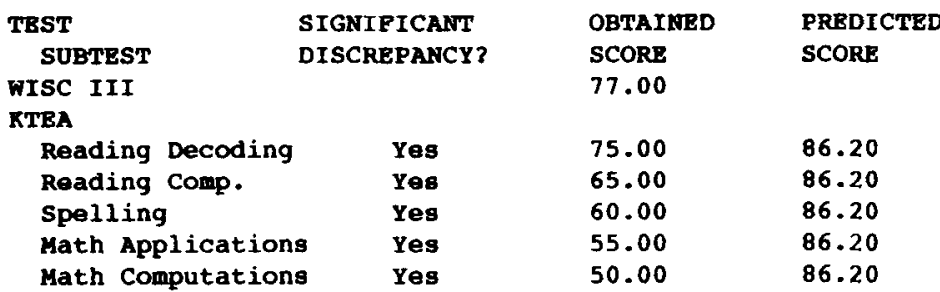

SEVBRITY RESULTS

\begin{tabular}{|c|c|c|c|c|c|}
\hline $\begin{array}{l}\text { TEST } \\
\text { SUBTEST }\end{array}$ & $\begin{array}{l}\text { SEVBRE } \\
\text { DISCREP . ? }\end{array}$ & $\begin{array}{l}\text { DISCREP. } \\
\text { SIZE }\end{array}$ & $\begin{array}{l}\text { CRITICAL } \\
\text { VALUE }\end{array}$ & $\begin{array}{l}\text { PROBABILITY } \\
\text { Of SEVERITY }\end{array}$ & $\begin{array}{l}\text { DISCREPA } \\
\text { OCCURREN }\end{array}$ \\
\hline \multicolumn{6}{|l|}{ KTBA } \\
\hline Reading Decoding & No & 11.20 & 17.56 & 1.00 & 17.62 \\
\hline Reading Comp. & Yes & 21.20 & 16.33 & 23.58 & 3.84 \\
\hline spelling & Yes & 26.20 & 16.92 & 72.91 & 1.47 \\
\hline Math Applications & Yes & 31.20 & 15.28 & 94.74 & 1.00 \\
\hline Math Computations & Yes & 36.20 & 15.79 & 99.00 & 1.00 \\
\hline
\end{tabular}

End Printout Serial Number I30000123

Figure 1. Example of the Standard Score Comparison 2.0 printed output.

such as the Wechsler Individual Achievement Test (Psychological Corp., 1992) provide scores that emphasize consideration of all seven areas. Future software may need to address increased interest in all seven severe discrepancy areas by correcting for additional multiple comparisons and calculating up to seven discrepancies in a single run.

2. Allowance for a second predictor measure of achievement. SSC 2.0 regresses achievement on a single predictor (IQ), but future software may provide increased prediction accuracy by permitting regression based on two IQ scores or an IQ score and a second variable.

3. Weighting of scores of the same achievement area. States such as Arkansas require that a student be given a second measure of achievement to confirm initially identified deficits. However, no method is offered, for example, to resolve differences in two reading comprehension scores so that a single score can be entered into a discrepancy model. Future regression software should offer an option to weight the obtained achievement scores, and to base results on the weighted composite.

4. The majority of regression software has been designed by field psychologists and has suffered from lack of flexibility in user interface and documentation. Future software should benefit from collaboration with professional programmers who can update the interfaces as necessary to support desktop buses, windows, pull-down menus, on-line help, and various printer drivers. 


\section{REFERENCES}

Evans, L. D. (1990). A conceptual overview of the regression discrepancy model for determining severe discrepancy between IQ and achievement scores. Journal of Learning Disabilities, 23, 406-412. Evans, L. D. (1991). Standard score comparison 2.0 [Computer program]. North Little Rock, AR: WtL.

Evans, L. D. (1992a). Multiple IQ-achievement comparisons: Effects on severe discrepancy determination. Learning Disability Quarterly, $15,167-174$

Evans, L. D. (1992b). Severe does not always imply significant: Bias of a regression discrepancy model. Journal of Special Education, 26, 57-67.

Evans, L. [D.], \& HILDEN, A. (1986). Regression analysis program [Computer program]. Helena, MT: Office of Public Instruction.

Forness, S. R., Sinclair, E., \& Guthrie, D. (1983). Learning disability discrepancy formulas: Their use in actual practice. Learning Disability Quarterly, 6, 107-114.

Frankenberger, W., \&Ronzaglio, K. (1991). A review of states' criteria and procedures for identifying children with learning disabilities. Journal of Learning Disabilities, 24, 495-500.

FURLONG, M. J. (1985). Ability-achievement discrepancy [Computer program]. Burlington, NC: Southern Micro Systems.

HammiLL, D. D. (1990). On defining learning disabilities: An emerging consensus. Journal of Learning Disabilities, 23, 74-84.
Iowa Department of Public Instruction (1981). The identification of pupils with learning disabilities. Des Moines, IA: Author.

Macmann, G. M., Barnett, D. W., Lombard, T. J., BeltonKOCHER, E., SHARPE, M. N. (1989). On the actuarial classification of children: Fundamental studies of classification agreement. Journal of Special Education, 23, 127-149.

Mercer, C. D., King-Sears, P., \& Mercer, A. R. (1990). Learning disability definitions and criteria used by state education departments. Learning Disability Quarterly, 13, 141-152.

Psychological CoRporation (1992). Wechsler Individual Achievement Test. San Antonio, TX: Author.

REYNolds, C. R. (1984). Critical measurement issues in learning disabilities. Journal of Special Education, 18, 451-476.

REYNOLDS, C. R., \& STOWE, M. L. (1985). Severe discrepancy analysis [Computer program]. Bensalem, PA: Train.

THORNDIKE, R. L. (1963). The concepts of over- and underachievement. New York: Teachers College Press, Columbia University.

Tomko, T. M., \& CAMPBELL, F. (1989). A screening strategy for learming disabled student. Unpublished manuscript, Edmonton Catholic School System, Edmonton, Canada.

U.S. OfFiCE of EduCation (1977). Assistance to states for education of handicapped children: Procedures for evaluating specific learning disabilities. Federal Register, 42, 65082-65085.

Washington OFFICE OF PUBLIC INSTRUCTION (1984). The identification of students as learning disabled. Olympia, WA: Author. 